\title{
Research on Global Higher Education Quality Based on BP Neural Network and Analytic Hierarchy Process
}

\author{
Mei Yuan, Chunyang Li \\ Chengdu Neusoft University, Chengdu, China \\ Email:2551161628@qq.com, 1377759045@qq.com
}

How to cite this paper: Yuan, M. and $\mathrm{Li}$, C.Y. (2021) Research on Global Higher Education Quality Based on BP Neural Network and Analytic Hierarchy Process. Journal of Computer and Communications, 9, 158-173.

https://doi.org/10.4236/jcc.2021.96009

Received: May 15, 2021

Accepted: June 26, 2021

Published: June 29, 2021

Copyright $\odot 2021$ by author(s) and Scientific Research Publishing Inc. This work is licensed under the Creative Commons Attribution International License (CC BY 4.0).

http://creativecommons.org/licenses/by/4.0/

\begin{abstract}
Having a universal, fair, democratic and practical higher education system plays a particularly important role in the future development of the country. However, the higher education system in various countries is uneven. It is of great significance to establish a general evaluation system for the development of global education. In this paper, 23 indicators are preliminarily selected from the education data of Universitas 21 and Global Statistical Yearbook. After the gray correlation analysis, 12 indicators were selected. On the one hand, principal component analysis is used to reduce the dimension of these 12 indicators in 50 countries, and the first four principal components with cumulative contribution rate of $99 \%$ are finally selected as the input parameters of BP neural network. On the other hand, 12 indicators are divided into four aspects as the standard of scheme decision-making. Finally, a higher education quality evaluation and decision-making model based on BP neural network and analytic hierarchy process are established. Then eight countries are selected to use the model to evaluate their current higher education quality. Based on the input and evaluation results of the four aspects of higher education in various countries, the analytic hierarchy process is used to make program decision, and several improvement suggestions are put forward for the current education policies of various countries.
\end{abstract}

\section{Keywords}

Higher Education, Gray Correlation Analysis, Main Component Analysis, BP Neural Network, Hierarchical Analysis, Evaluation Index System

\section{Introduction}

The quality of higher education has become increasingly prominent, coupled 
with the different educational evaluation systems in various countries, which is not conducive to unified evaluation and planning. How to ensure the quality of higher education has become an urgent global problem. At present, in the existing evaluation system of some countries, the evaluation objectives are mainly the quality of higher education and the universities themselves [1]. However, this is too general to accurately evaluate the teaching objectives and school-running needs of various types of universities. In many countries, the aspects involved in the process of evaluating universities are often referred to the CIPP (background, input, process, output) evaluation model of Staverbim [2]. But the evaluation index system of each country is different, such as IMHE/OECD, ACE-CIGE, JSPS, AUQA/TEQSA [3]. Therefore, the introduction of a general evaluation index system to guide the healthy and sustainable development of universities is an important task of the current global higher education reform and development [4]. It is of great significance for the rational evaluation of education in the world.

In this paper, combined with the above mainstream evaluation system, from the U21 and global statistical yearbook education related to many data. Data processing was conducted through grey correlation analysis, and 12 quantitative and qualitative statistical indicators were selected [5]. Then the first five principal components were extracted by principal component analysis, and the 12 indicators were divided into four aspects as the standard of scheme decision. The evaluation and decision-making model of higher education quality based on BP neural network and analytic hierarchy process is established. The education data of 50 countries in 2019 and 2020 are used for many times for model training and testing, and it is found that the error of the model is between 0.0025 and 0.0029 . Selecting eight countries and using the model to evaluate their education quality, it is found that the United States has the best higher education system, followed by Switzerland, Britain, Sweden, Taiwan-China, Ukraine, Turkey and Thailand. By comparing the differences in factors such as education investment among countries, it is found that the model results are reasonable. Combined with the current investment and evaluation results of each country in four aspects of higher education, the analytic hierarchy process is used to further make decisions on the quality of education in three countries with low educational scores (Ukraine, Turkey and Thailand), and several suggestions for improvement of educational policies are put forward.

\section{Data Processing and Analysis}

\subsection{Data Processing}

By collecting various factors affecting higher education in various countries and referring to various relevant literature, 23 indicators were preliminarily screened [6]. Including input indicators, process indicators and input indicators of three categories [7], specific indicators see Table 1 .

After dimensionless processing and consistent processing, the grey correlation 
Table 1. Summary table of various indicators.

\begin{tabular}{clc}
\hline Index & \multicolumn{1}{c}{ Content } & Number \\
\hline Investment index & $\begin{array}{l}\text { Government expenditure on education (\% of GDP), total number } \\
\text { of books, education funding, total enrollment rate of higher } \\
\text { education, faculty (proportion of masters and doctors), educational } \\
\text { opportunities (probability of enrollment), degree value, education } \\
\text { quality, research level, dissertation Number of outstanding } \\
\text { scientists, number of major scientific research projects }\end{array}$ & 12 \\
Process index & $\begin{array}{l}\text { Student-teacher ratio, fairness (male to female ratio) } \\
\text { Output index }\end{array}$ & $\begin{array}{l}\text { Student ratio, number of dominant disciplines, school reputation, } \\
\text { quality of scientific research results, number of national key } \\
\text { disciplines, number of outstanding people, social reputation, } \\
\text { number of paper citations, employment rate }\end{array}$ \\
\hline
\end{tabular}

degree is used to analyze the influence degree of each index on the quality of higher education. Finally, 12 indexes are selected, including teacher-student ratio, government education expenditure, total enrollment rate of higher education, employment rate, international student ratio, education quality, research level, number of paper citations, teaching staff, number of advantageous disciplines, quality of scientific research achievements and social reputation. The specific process is as follows.

The new data are obtained by quantifying the data, and then the invalid data and missing data are eliminated to form a new data set. Then, gray correlation analysis is used to calculate the impact of each indicator on platform pricing for the 23 indicators in the new dataset. In order to further extract effective information, the specific process of grey correlation analysis is as follows:

\section{1) Data normalization}

Due to the data exist some items of the numerical value is relatively large, some items of the numerical value is relatively small, so the impact on the pricing results will be different. Items with larger values may have a decisive impact on pricing. In order to make each index close to the result gap, the data are normalized as follows:

$$
x_{k}=\frac{x_{k}-x_{\min }}{x_{\max }-x_{\min }}
$$

Among them, $x_{\min }$ is the minimum value among the values in the index, and $x_{\max }$ is the maximum value among the values in the index.

2) Find the difference sequence, maximum difference and minimum dif-

\section{ference}

Difference sequence: Consists of the absolute value of the difference between $x_{0}^{\prime}$ and $x_{i}^{\prime}$ corresponding to point $k$

$$
\Delta_{o i}(k)=\left|x_{0}(k)^{\prime}-x_{i}(k)^{\prime}\right|, \quad(k=1,2, \cdots, N)
$$

Maximum difference between two levels: 


$$
\max _{i k}\left|x_{0}(k)^{\prime}-x_{i}(k)^{\prime}\right|
$$

Minimum difference between two levels:

$$
\min _{i k}\left|x_{0}(k)^{\prime}-x_{i}(k)^{\prime}\right|
$$

3) Calculate the gamma between factors

$$
\xi_{o i}(k)=\frac{\min _{i k}\left|x_{0}(k)^{\prime}-x_{i}(k)^{\prime}\right|+\xi \cdot \max _{i k}\left|x_{0}(k)^{\prime}-x_{i}(k)^{\prime}\right|}{\Delta_{o i}(k)+\xi \cdot \max _{i k}\left|x_{0}(k)^{\prime}-x_{i}(k)^{\prime}\right|}
$$

Among them, $\xi$ is the resolution coefficient, and the coefficient result is generally in the range of $(0,1)$. The smaller the $\xi$, the greater the resolution.

4) Calculate the degree of grey correlation

$$
\gamma_{o i}=\frac{1}{N} \sum_{k=1}^{N} \xi_{o i}(k)
$$

Through gray correlation analysis, 13 indexes with the highest correlation degree are selected as shown in Figure 1.

\subsection{Analysis of Data}

Through data processing, it can be found that the impact indicators of higher education quality tend to be roughly consistent, and the comprehensiveness of the indicators with larger impact weights is relatively strong. Such as education quality, government education expenditure, social reputation, research level, etc. In addition, these indicators are characterized by input and output indicators, and process indicators are slightly involved. Among them, the indicators reflecting educational input can be measured by human, material and financial resources, emphasizing the resources invested. Process indicators emphasize the operation mechanism of transforming the resources invested in educational activities into teaching, scientific research achievements and social service. The output index refers to the outcome index of output and the benefit index reflecting the school-running results. Compared with the previous mainstream

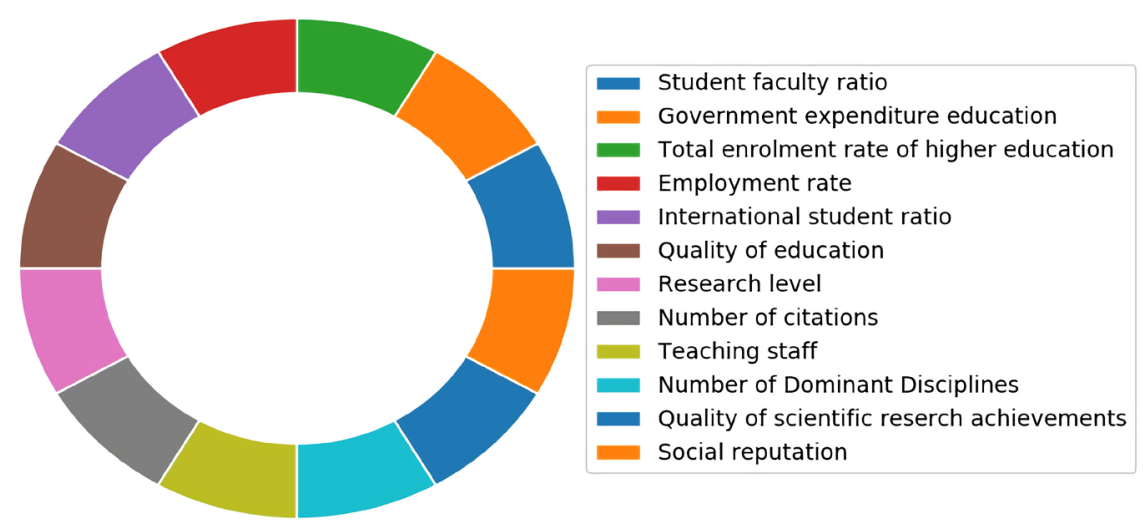

Figure 1. Higher education evaluation index. 
evaluation index system [8], it is found that higher education evaluation is based on these aspects, so the selected indicators are reasonable.

\section{Model Building}

\subsection{Evaluation Model Based on Principal Component Analysis}

Principal component analysis is a multivariate statistical method to examine the correlation between multiple variables. It studies how to reveal the internal structure of multiple variables through a small number of principal components, that is, to derive a small number of principal components from the original variables so that they can retain as much information as possible of the original variables and are not correlated with each other. In this paper, eight countries are selected as the evaluation objects. Principal component analysis is used to reduce the dimension of each index after grey correlation analysis, which is ready for the subsequent BP neural network prediction. The specific process is as follows.

\section{1) Data standardization}

There are 12 index variables in this question, each of which is $x_{1}, x_{2}, \cdots, x_{8}$, and there are 8 evaluation objects in total. The value of the $j$-th index of the $i$-th evaluation object is converted into a standard index value $\widetilde{a_{i j}}$

$$
\begin{gathered}
\widetilde{a_{i j}}=\frac{a_{i j}-\mu_{i j}}{s_{i j}}(i=1,2, \cdots, 12 ; j=1, \cdots, 8) \\
\mu_{i j}=\frac{1}{n} \sum_{i=1}^{n} a_{i j} \\
s_{j}=\sqrt{\frac{1}{n-1} \sum_{n-1}^{n}\left(a_{i j}-\mu_{j}\right)^{2}},(j=1, \cdots, 8) \\
\widetilde{x_{j}}=\frac{x_{j}-\mu_{j}}{s_{j}},(j=1,2, \cdots, 8)
\end{gathered}
$$

2) Calculate the correlation coefficient matrix

$$
\begin{gathered}
R=\left(r_{i j}\right)_{m \times m} \\
r_{i j}=\frac{\sum_{k=1}^{n} \widetilde{a_{k i}} \cdot \widetilde{a_{k j}}}{n-1},(i, j=1,2, \cdots, 8)
\end{gathered}
$$

\section{3) Find eigenvalues and eigenvectors}

Calculate the eigenvalue $\lambda_{1} \geq \lambda_{2} \geq \cdots \geq \lambda_{8} \geq 0$ of the correlation coefficient matrix $R$ and the corresponding eigenvector $\mu_{1}, \mu_{2}, \cdots, \mu_{8}$. Where $\mu_{j}=\left[\mu_{1 j}, \mu_{2 j}, \cdots, \mu_{5 j}\right]^{\mathrm{T}}, m$ new indicator variables are composed of feature vectors.

$$
\left\{\begin{array}{c}
y_{1}=u_{11} \widetilde{x_{1}}+u_{21} \widetilde{x_{2}}+\cdots+u_{m 1} \widetilde{x_{m}} \\
\vdots \\
y_{m}=u_{1 m} \widetilde{x_{1}}+u_{2 m} \widetilde{x_{2}}+\cdots+u_{m m} \widetilde{x_{m}}
\end{array}\right.
$$

where $y_{1}$ is the first principal component, $y_{2}$ is the second principal component, $y_{1}, \cdots, y_{m}$ is the $m$-th principal component. 


\section{4) Select principal components}

Select $p(p \leq m)$ principal components to calculate the comprehensive evaluation value. The information contribution rate of its eigenvalue $r_{i j}$ is

$$
b_{i}=\frac{\lambda_{j}}{\sum_{k=1}^{m} \lambda_{k}},(j=1,2, \cdots, m)
$$

The cumulative contribution rate of the main component $y_{1}, y_{2}, \cdots, y_{p}$ is

$$
a_{p}=\frac{\sum_{k=1}^{p} \gamma_{k}}{\sum_{k=1}^{10} \gamma_{k}}
$$

when $a_{p}$ is close to 1 (usually $a_{p}=0.85,0.90,0.95$ ), the first $p$ index variables $y_{1}, y_{2}, \cdots, y_{p}$ are selected as $p$ principal components instead of the original $m$ index variables, so that the $p$ principal components can be comprehensively evaluated.

\subsection{BP Neural Network Prediction Model}

BP neural network is a multi-layer feed-forward network trained by error back propagation (referred to as error back propagation). Its algorithm is called BP algorithm. Its basic idea is gradient descent method. Using gradient search technology, the error mean square deviation of the actual output value and the expected output value of the network is minimized. The data processed by principal component analysis are transferred into the neural network to predict the quality of higher education as follows. Its neural network structure is shown in Figure 2.

According to the BP neural network, build the model, the main steps are as follows:

1) Input layer: The input is the first $m$ principal components obtained through principal component analysis. For multi-sample input, the expression is as follows:

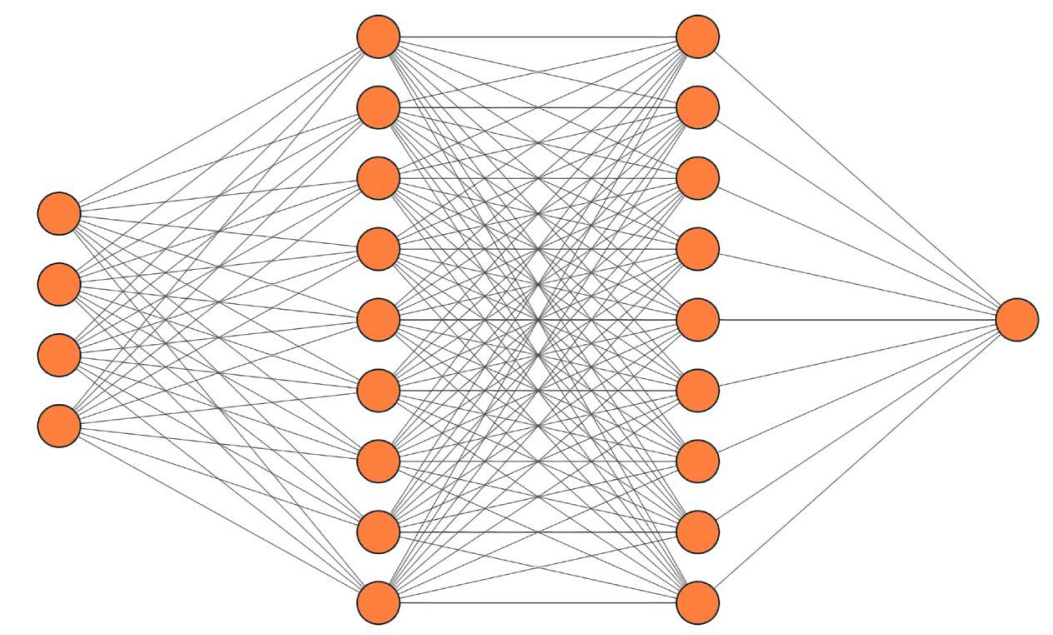

Input Layer $\in \mathbb{R}^{4}$

Hidden Layer $\in \mathbb{R}^{9}$

Hidden Layer $\in \mathbb{R}^{9}$

Output Layer $\in \mathbb{R}$

Figure 2. BP neural network structure diagram. 


$$
\begin{gathered}
Z^{[l]}=w^{[l]} A^{[l-1]}+b^{[l]} \\
A^{[l]}=\sigma\left(Z^{[l]}\right) \\
A^{[l]}=\left[\begin{array}{cccc}
\mid & \mid & \cdots & \mid \\
a^{[l-1](1)} & a^{[l-1](2)} & \cdots & a^{[l-1](m)} \\
\mid & \mid & \cdots & \mid
\end{array}\right]
\end{gathered}
$$

Among them, $A$ is the input matrix, $w$ is the weight, and $b$ is the bias.

2) Hidden layer: Use activation function to perform nonlinear transformation. The sigmoid function is used as the activation function here.

$$
\sigma(Z)=\frac{1}{1+\mathrm{e}^{-z}}
$$

3) Output layer: The loss function mainly refers to the loss or error of a single sample; the cost function represents the overall error when multiple samples are simultaneously input to the model-the sum of the errors of each sample is then averaged. For $m$ samples, the loss function expression is as follows:

$$
C=-\frac{1}{m} \sum_{i=0}^{m}\left(y^{(i)} \log \left(a^{(i)}\right)+\left(1-y^{(i)}\right) \log \left(1-a^{(i)}\right)\right)
$$

4) Reverse transfer and update parameters: According to the principle of gradient descent, the parameters are updated in the opposite direction of the gradient.

Output layer error:

$$
d Z^{[L]}=\nabla_{A} C \odot \sigma^{\prime}\left(Z^{[l]}\right)
$$

Hidden layer error:

$$
d Z^{[L]}=\left[w^{[l+1]} d Z^{[l+1]}\right] \odot \sigma^{\prime}\left(Z^{[l]}\right)
$$

Parameter change rate:

$$
\begin{gathered}
d b^{[l]}=\frac{\partial C}{\partial b^{[l]}}=\frac{1}{m} \text { mean Of Each Row }\left(d Z^{[l]}\right) \\
d w^{[l]}=\frac{\partial C}{\partial w^{[l]}}=\frac{1}{m} d Z^{[l]} A^{[l-1] T}
\end{gathered}
$$

Parameter update:

$$
\begin{aligned}
& b^{[l]} \leftarrow b^{[l]}-\alpha \frac{\partial L}{\partial b^{[l]}} \\
& w^{[l]} \leftarrow w^{[l]}-\alpha \frac{\partial L}{\partial w^{[l]}}
\end{aligned}
$$

\subsection{Analytic Hierarchy Decision Model}

Analytic Hierarchy Process (AHP) is a practical multi-scheme or multi-objective decision-making method proposed by Professor T. L. Saaty, an American operational researcher in the 1970s. It is a combination of qualitative and quantitative decision-making analysis method. It is often used in multi-objective, mul- 
ti-criteria, multi-factor and multi-level unstructured complex decision-making problems, especially strategic decision-making problems, and has a very wide range of practicality. Based on the current input and evaluation results of four aspects of higher education in various countries, the analytic hierarchy process is used to make the program decision as follows. There are five steps to analyze the problem with AHP:

\section{1) Build a hierarchical model}

The decision objectives, the factors considered (decision criteria) and the decision objects are divided into the highest layer, the middle layer and the lowest layer according to their relationship. The hierarchical structure diagram is shown in Figure 3.

The criterion layer $\mathrm{R}$ represents resource input, $\mathrm{E}$ represents teaching environmental factors, $\mathrm{C}$ represents connectivity factors, and $\mathrm{O}$ represents educational output [9].

\section{2) Hierarchical single sort}

The so-called single-level ranking refers to the ranking of the importance of each factor of the current level for a certain factor at the upper level.

3) The method of finding the largest eigenvalue of judgement matrix and its corresponding eigenvector

a) Normalize each column of the matrix

$$
\delta=\frac{b_{i j}}{\sum_{i=1}^{n} b_{i j}}
$$

b) Normalize the matrix of the case column, and then sum by row

$$
\varpi=\left(\varpi_{1}, \varpi_{2}, \cdots, \varpi_{n}\right)^{\mathrm{T}}
$$

c) Normalize the vector

$$
\omega_{i}=\frac{\varpi_{i}}{\sum_{j=1}^{n} \varpi_{i}}
$$
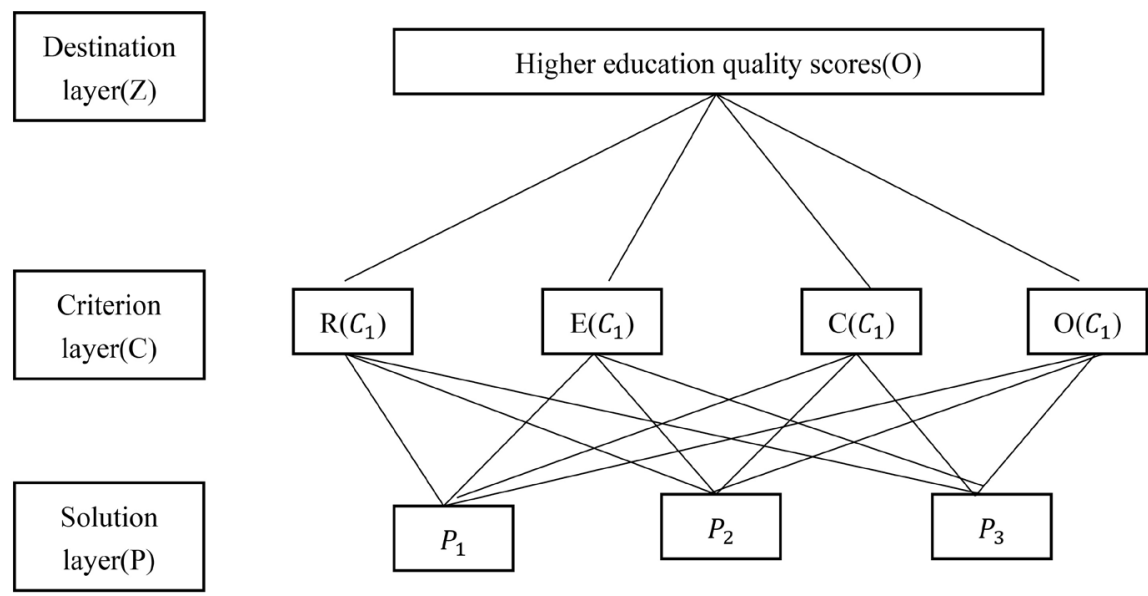

Figure 3. Hierarchical analysis decision diagram. 
d) Calculate the largest characteristic root

$$
\lambda_{\max }=\sum_{i=1}^{n} \frac{(B \omega)_{i}}{n \omega_{i}}
$$

\section{4) Consistency test of judgment matrix}

The so-called consistency refers to the logical consistency of judgment thinking. For example, when $\mathrm{A}$ is more important than $\mathrm{C}$, and $\mathrm{B}$ is slightly more important than $\mathrm{C}$, then A must be more important than $\mathrm{B}$. This is the logical consistency of judgment thinking, otherwise there will be contradictions in judgment.

a) Consistency index

$$
C I=\frac{\lambda-n}{n-1}
$$

b) Concordance ratio

$$
C R=\frac{C I}{R I}
$$

c) Random Consistency Index RI, Principle of Value Reference Table 2.

Among them, when $a=0, C I$ is consistent; the larger $C I$, the more serious the inconsistency of A. When $C R<0.1$, the inconsistency of $\mathrm{A}$ is within the allowable range, and the eigenvector of A can be used as the weight vector.

\section{5) Total rank order}

Determine all factors for the sequencing weights of the relative importance of the total target, called hierarchical total sorting.

This process is in turn from the highest layer to the bottom. For the highest layer, the results of its hierarchical order are the results of the total sort.

$C$ layer $m$ factors $C_{1}, C_{2}, \cdots, C_{5}$, the order of the total target $O$ is the $n$ factors of the $\omega=\alpha_{1}, \alpha_{2}, \cdots, \alpha_{m}, P$ layer, and the upper layer $C$ of the factor $C_{j}$ is sorted as $b_{1 j}, b_{2 j}, \cdots, b_{n j}(j=1,2, \cdots, m)$.

a) The total number of layers of the $P$ layer is:

$$
\left\{\begin{array}{c}
P_{1}: \alpha_{1} b_{11}+\alpha_{2} b_{12}+\cdots+\alpha_{m} b_{1 m} \\
P_{2}: \alpha_{1} b_{21}+\alpha_{2} b_{22}+\cdots+\alpha_{m} b_{2 m} \\
\vdots \\
P_{n}: \alpha_{1} b_{n 1}+\alpha_{2} b_{n 2}+\cdots+\alpha_{m} b_{n m}
\end{array}\right.
$$

b) The value of the $P$ layer is the weight of the total target:

$$
\sum_{j=1}^{n} \alpha_{j} b_{i j}
$$

c) A hierarchical ranking, the results of which are shown in Table 3.

Table 2. Consistent index $R I$ selection table.

\begin{tabular}{cccccccccccc}
\hline $\boldsymbol{n}$ & $\mathbf{1}$ & $\mathbf{2}$ & $\mathbf{3}$ & $\mathbf{4}$ & $\mathbf{5}$ & $\mathbf{6}$ & $\mathbf{7}$ & $\mathbf{8}$ & $\mathbf{9}$ & $\mathbf{1 0}$ & $\mathbf{1 1}$ \\
\hline $\boldsymbol{R I}$ & 0 & 0 & 0.58 & 0.90 & 1.12 & 1.24 & 1.32 & 1.41 & 1.45 & 1.49 & 1.51 \\
\hline
\end{tabular}


Table 3. Hierarchical total ranking table.

\begin{tabular}{|c|c|c|}
\hline & $\begin{array}{l}C_{1}, C_{2}, \cdots, C_{m} \\
\alpha_{1}, \alpha_{2}, \cdots, \alpha_{m}\end{array}$ & B's level total sorted $P \times C$ \\
\hline$\left\{\begin{array}{l}P_{1} \\
P_{2} \\
\vdots \\
P_{n}\end{array}\right.$ & $\left\{\begin{array}{c}b_{11}, b_{12}, \cdots, b_{1 m} \\
b_{21}, b_{22}, \cdots, b_{2 m} \\
\vdots \\
b_{n 1}, b_{n 2}, \cdots, b_{n n}\end{array}\right.$ & $\left\{\begin{array}{c}\sum_{j=1}^{m} \alpha_{j} b_{1 j}=b_{1} \\
\sum_{j=1}^{m} \alpha_{j} b_{2 j}=b_{2} \\
\vdots \\
\sum_{j=1}^{m} \alpha_{j} b_{n j}=b_{n}\end{array}\right.$ \\
\hline
\end{tabular}

\section{Experiment}

\subsection{Model Application and Vision}

Firstly, by selecting 23 indicators related to national higher education and using gray correlation analysis to analyze the impact of each indicator on the comprehensive score results, 12 indicators with the greatest impact are retained. Then, the data of 50 countries are gathered, and the first four principal components are extracted by principal component analysis. These four component factors are used as new inputs, and the comprehensive score is used as the final result. The final prediction model is optimized by BP neural network. The BP neural network model is used to randomly select the first four principal components of eight countries in 2019 and 2020. After standardized processing, the score prediction is carried out and compared with the real value. It is found that the final mean square error of the model in 2020 is 0.0025 , and the mean square error of 2019 is 0.0029 . The results are as follows: Figure 4 and Figure 5.

Through the experimental results, it can be found that the model has good results in the evaluation and prediction of various countries. Has certain versatility. However, the prediction effects for each country are different, but the individual errors are small. Therefore, the model can play a good reference effect for the quality assessment of higher education around the world.

\subsection{Measurement of the Current State of Higher Education Health}

Then, by comparing the assessment results of each country, it is found that the United States has the best higher education system among the eight countries currently projected, followed by Switzerland, Sweden, Britain, Taiwan-China, Ukraine, Turkey and Thailand. Among them, the higher education system of Ukraine, Turkey and Thailand is far behind that of the other five countries, with scores less than 50 points. For an in-depth analysis of the internal factors affecting the education score, the statistics of the changes in the higher education system score of the eight countries in the past three years are shown in Figure 6.

It can be seen from Figure 6 that the higher education scores of a few countries have fluctuated in the past three years, but the degree of fluctuation is relatively small. The quality scores of higher education in Ukraine and Turkey in the past three years showed a trend of first decrease and then increase. Thailand's 


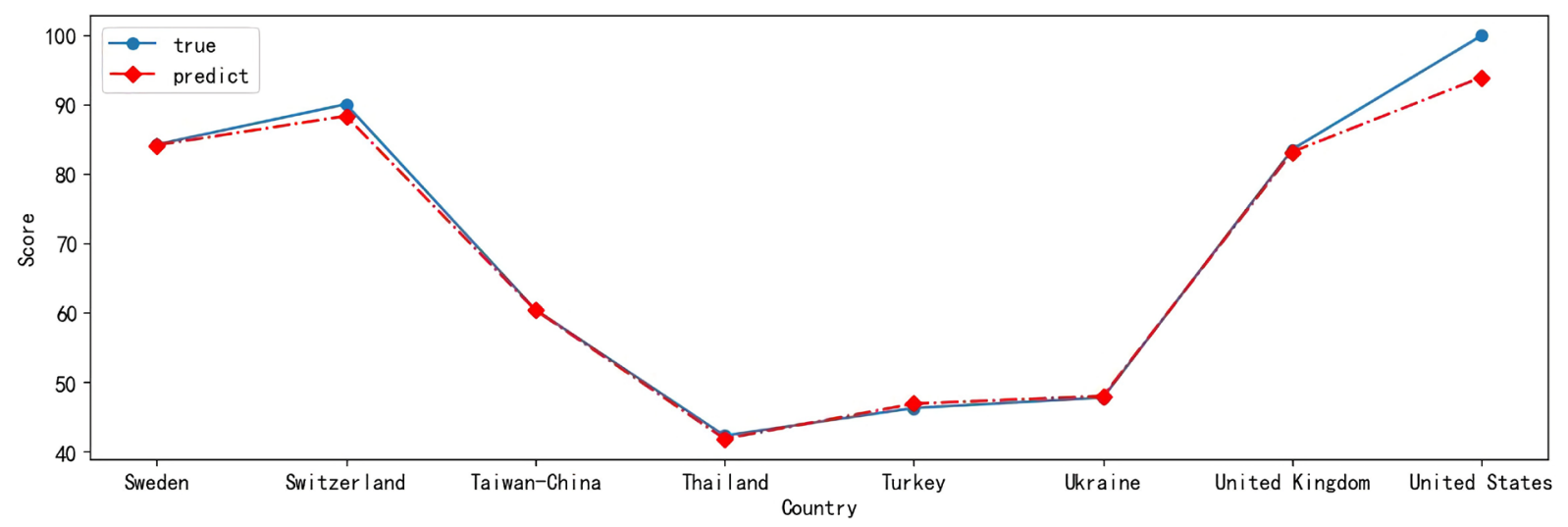

Figure 4. 2020 Forecast rating and real score relationship.

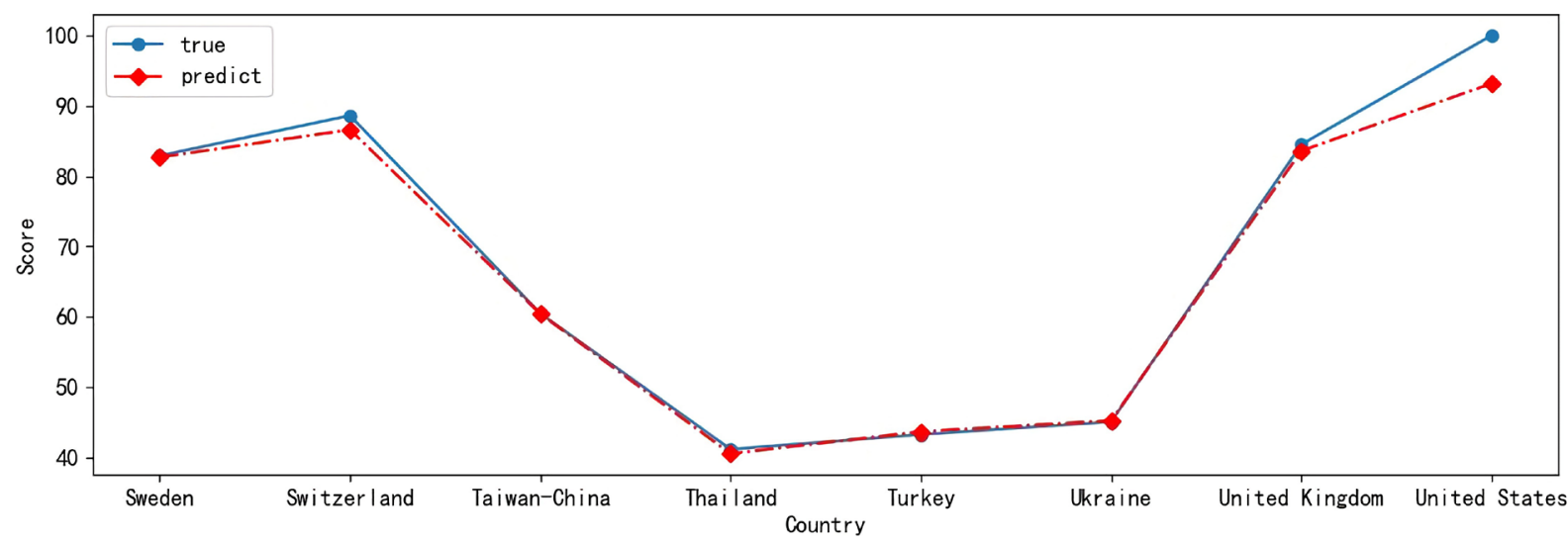

Figure 5. 2019 Forecast rating and real scoring relationship.

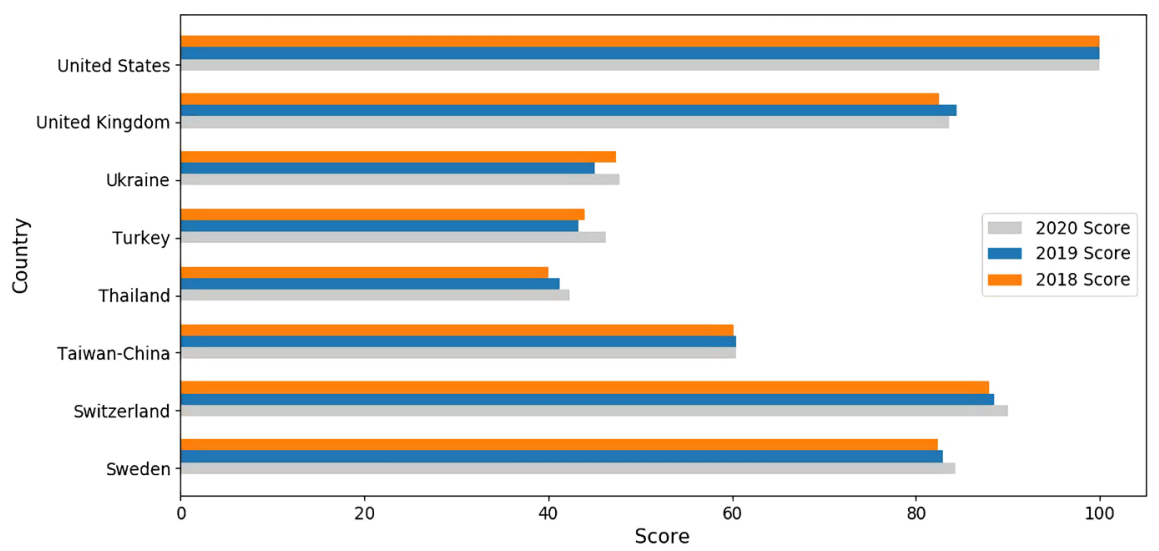

Figure 6. Changes in education score in each country.

higher education quality score is in a state of continuous growth. We further explore the internal reasons for the changes in the quality score of higher education. By comparing the changes in education index and education investment in recent years in various countries, the results are shown in Figure 7 and Figure 8.

Through the above figure, it can be found that countries with better quality of higher education such as the United States have a large proportion of annual 


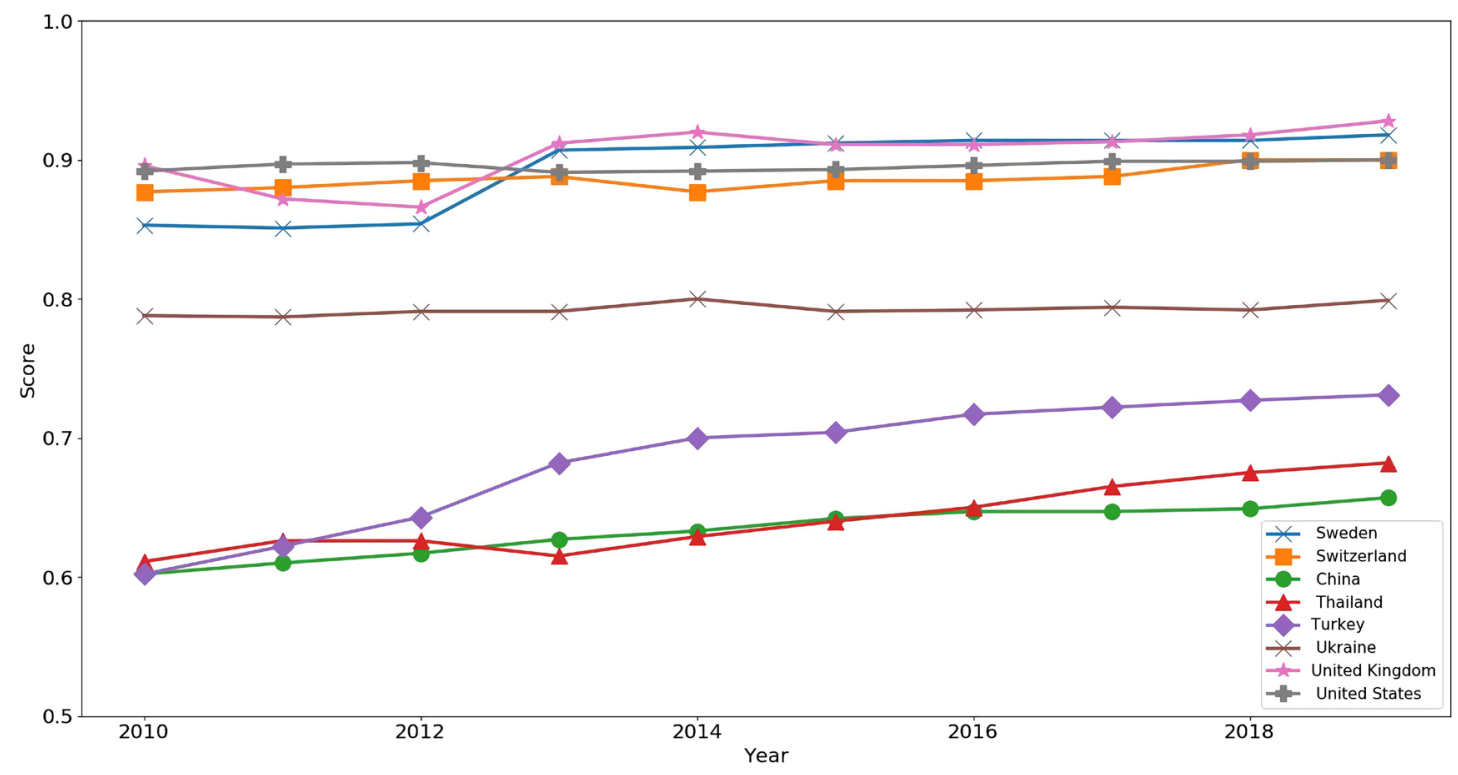

Figure 7. Trend chart of education index in each country in recent ten years.

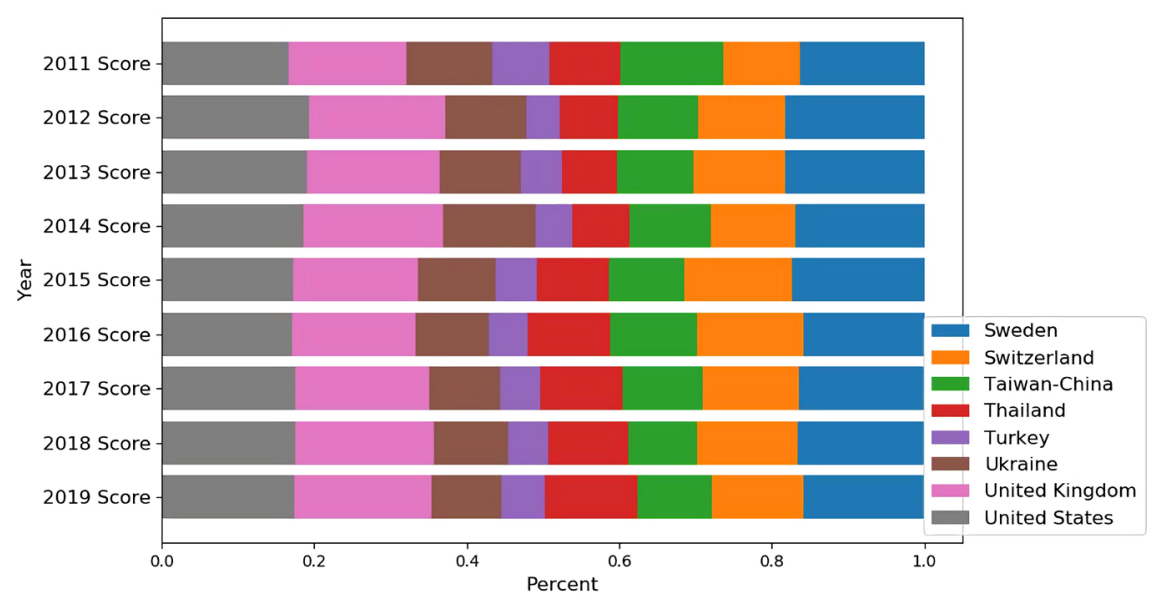

Figure 8. Figures on changes in educational inputs in countries over the past nine years.

educational investment in the gross national product [10] and the quality of education is also significant. Turkey's education index has been significantly improved compared with the previous decade. Although its investment in education funds has also been fluctuating in the past decade, the quality score of higher education in the past three years has been significantly reduced compared with the previous six years. The education index of Thailand in recent ten years is in a state of fluctuating growth, but the investment in education in recent three years is much less than the previous six years, and the quality score of higher education is also slightly reduced. Ukraine's education index changes in the past decade are relatively stable, no significant increase or decrease. The quality score of higher education in the past three years was significantly lower than that in the previous six years, and the observation found that the investment in education funds was also reduced. It can be found that investment in 
education has a great impact on educational scoring, but not a decisive factor. Other factors led to the country's score fluctuations in the past three years. Such as environmental impact, government policy impact.

Further analysis of the data changes of the indicators shows that the output of Turkey and Thailand has increased slightly in recent years, but the teaching environment score has decreased significantly, and the final quality score of higher education has also decreased slightly. Although Ukraine's output increased slightly, its teaching environment score changed relatively smoothly, and the final higher education quality score was relatively stable.

By comparing the changes in various indicators, it reflects the corresponding national policies and the integrity of the education system [11]. Through the model projections, it is found that if this continues, the three countries will continue to maintain this trend in the short term in the future without significant changes.

\subsection{Suggest Implementation Policy and Implementation Schedule}

In order to make program decision and put forward some substantive suggestions for these three countries, the 12 indicators are divided into four categories, and the analytic hierarchy process is used to make the corresponding program decision, as shown in Table 4.

Through the above analysis, it is found that the current policy has a relatively slow effect on the development of higher education in the corresponding countries. Taking into account the country's human and material resources investment in education, teaching environment, internationalization and academic indicators and educational output development status, through the prediction of this model, this paper puts forward some development suggestions and implementation schedules for these three countries, as follows.

As can be seen from Figure 9, Turkey has invested more in resources and teaching environment in 2020, but has achieved little in output and coherence. Figure 10 shows that the input and teaching environment of educational resources are positively correlated with output, but there is no significant linear correlation with correlation. It shows that increasing the input of educational resources and focusing on the improvement of teaching environment in the short term are conducive to improving output. Compared with the relevant data in the United States, it is found that in order to achieve long-term improvement

Table 4. Division of specific categories of indicators.

\begin{tabular}{cl}
\hline Category & \multicolumn{1}{c}{ Index } \\
\hline Resources & Government education spending, teacher-student ratio, Teamwork \\
Teaching environment & Education quality, research level, number of advantageous disciplines \\
Connectivity & International proportion of international students, quote from the paper \\
Output & $\begin{array}{l}\text { Higher education general enrollment rate, quality of scientific research } \\
\text { results, social reputation, employment rate }\end{array}$ \\
\hline
\end{tabular}




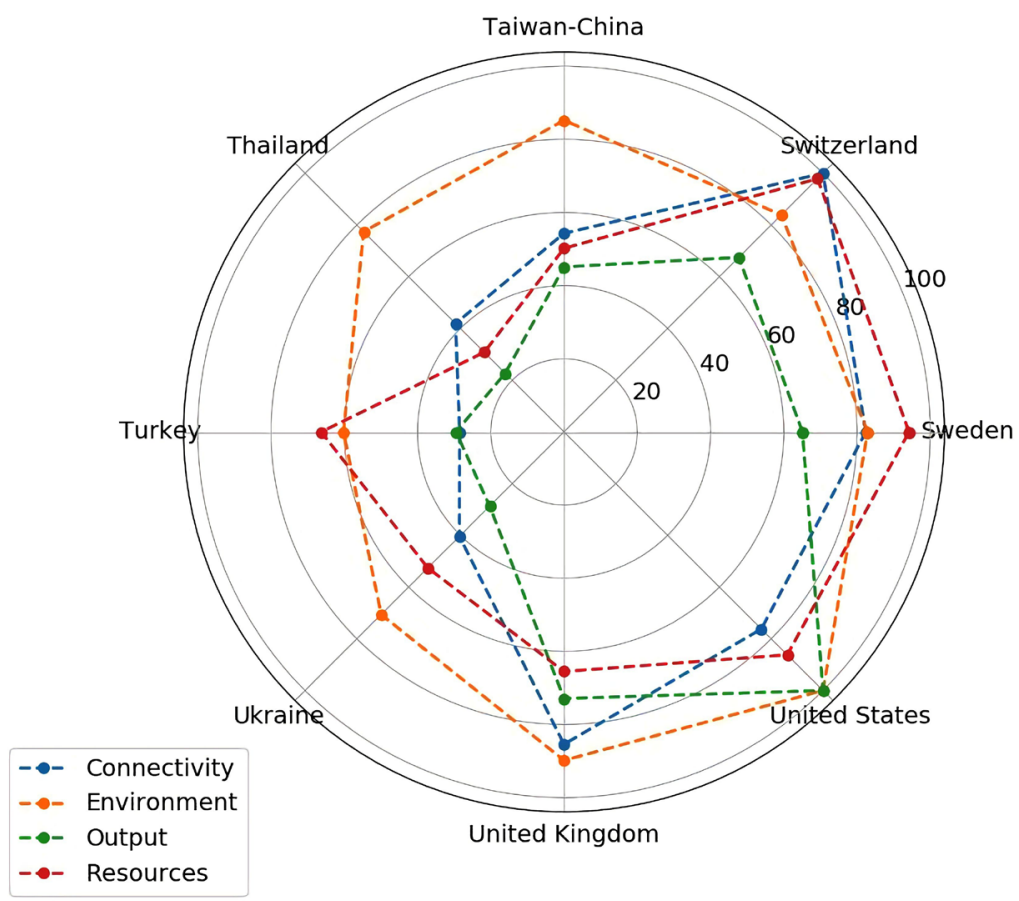

Figure 9. Figures of input-output ratio of eight countries in four aspects in 2020.
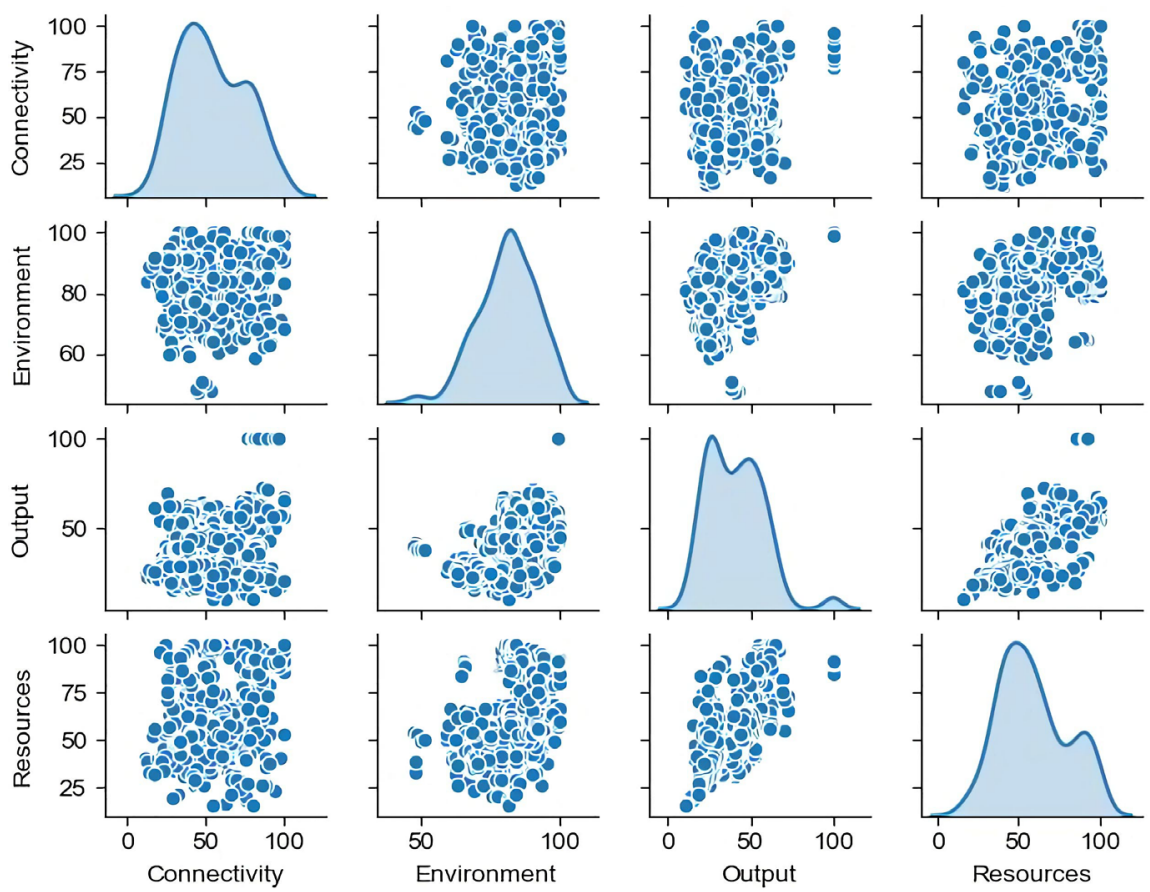

Figure 10. 8 joint distribution of data in four areas in countries.

in the quality of higher education, we should not only maintain the input of educational resources and focus on the improvement of teaching environment, but also pay attention to the output of educational quality, so as to spend a share of money and obtain a share of income [9]. Therefore, it is suggested that in the future, the country should not only maintain the input of educational resources 
and pay attention to the improvement of teaching environment, but also pay attention to the output of educational quality to achieve the purpose of long-term steady improvement.

Thailand's teaching environment score is relatively high, but the output is seriously insufficient. It can be found that the investment in teaching resources is relatively small, so moderately increasing the investment in teaching resources will greatly help improve the overall teaching quality. It is suggested that countries should increase investment in teaching resources in the near future.

Ukraine and Thailand have similarities. The teaching environment scores are high, but the investment in teaching resources is also insufficient. A little different is its output is significantly higher than Thailand. The observation found that it invested more in teaching resources than Thailand. It is suggested that in the short term in the future, the country should appropriately invest in teaching resources, continue to pay attention to output efficiency, and achieve the purpose of improving the quality of higher education in the country as a whole.

\section{Conclusions}

Through the model, it can be found that the input of teaching resources in higher education in countries with relatively backward higher education is obviously insufficient, so the output is relatively low. These countries pay more attention to environmental inputs, as do countries with higher quality education. However, the difference is that countries with better quality of higher education pay more attention to output and connectivity. It can be found that increasing the input of educational resources in the short term will slightly improve the quality of higher education, but in order to achieve long-term benefits, more attention should be paid to the output and connectivity of teaching while creating a high-quality teaching environment. There are still some backward education countries do not know how to effectively improve the level of higher education [12], blindly increase the input of teaching resources will not last earnings, but will be counterproductive. For countries whose education system is not mature enough, it is the key to create a high-quality teaching environment, pay attention to the talent training mechanism and improve the output of education.

Through a detailed analysis of the current higher education quality in the above countries, it is found that the global higher education quality assessment and decision-making model proposed in this paper has achieved remarkable results in many countries with different levels of economic development. Has certain versatility. A simple and easy-to-understand model is used to solve the complex problem of different evaluation standards of higher education in the world and it is difficult to provide comprehensive solutions. It has a certain use value and provides a new solution for the quality assessment and policy decision-making of higher education in the world in the future.

\section{Conflicts of Interest}

The authors declare no conflicts of interest regarding the publication of this paper. 


\section{References}

[1] Ren, Y.C. (2014) Research on the Characteristics and Trend of Ranking Indicator System at Home and Abroad. Master's Thesis, Zhejiang Normal University, Hangzhou.

[2] Zhang, S.H. (2020) Research on the Construction of Higher Education Evaluation System under the Background of Big Data. Journal of Tianjin Academy of Education, 1, 62-65.

[3] Liu, Y. and Li, N. (2019) Construction of the Comprehensive Evaluation Index System of the Internationalization Capability of Higher Education. Efficient Education Management, 13, 53-59.

[4] Huang, H.J. (2014) Research on Hierarchical Analysis and Fuzzy Comprehensive Evaluation Method in Public Policy Evaluation. Master's Thesis, Central China Normal University, Wuhan.

[5] Alsarmi, A.M. and Al-Hemyari, Z.A. (2014) Quantitative and Qualitative Statistical Indicators to Assess the Quality of Teaching and Learning in Higher Education Institutions. International Journal of Information and Decision Sciences, 6, 383-389. https://doi.org/10.1504/IJIDS.2014.066631

[6] St George, E. (2020) Higher Education Quality and Autonomy-A Case Study of Lao PDR. Higher Education, 5, 2-8.

[7] Reda, N.W. (2017) Balanced Scorecard in Higher Education Institutions. Quality Assurance in Education, 9, 489-496.

[8] Liu, M.Y. (2013) Inquiry of the Status Quo of Sustainable Development of Higher Education in Asia. Education Vision, 20, 17.

[9] Bumjaid, S.E. and Malik, H.A.M. (2019) The Effect of Implementing of Six Sigma Approach in Improving the Quality of Higher Education Institutions in Bahrain. International Journal of Engineering and Management Research (IJEMR), 4, 134-138.

[10] Jurabaevich, S.N. and Kutbiddinovich, S.I. (2019) Economic Diagnostics of the Quality of Higher Education and the Basics of Its Modeling. South Asian Journal of Marketing \& Management Research, 8, 62-66.

[11] Wang, S.B. (2018) Research on the International Evaluation Index System of China Double and First Class University. Master's Thesis, East China Normal University, Shanghai.

[12] Ye, L. and Wang, Z.T. (2018) Internationalization of China Higher Education: A Type Frame and Evaluation. Compare Education Research, 5, 43-45. 